\title{
Integrating biological degradation potential into ecological risk assessment
}

\author{
$\underline{\text { Tang F. H. M. }}{ }^{\text {a }}$, la Cecilia D. ${ }^{\text {a }}$ Vervoort R.W. ${ }^{\text {d }}$ Coleman N. ${ }^{\text {, }}$ Conoley C. ${ }^{c}$ and Maggi F. ${ }^{a}$ \\ ${ }^{a}$ Laboratory for Advanced Environmental Engineering Research, School of Civil Engineering, The \\ University of Sydney, Bld. J05, 2006 Sydney, NSW, Australia. \\ ${ }^{b}$ School of Life and Environmental Sciences, The University of Sydney, Sydney, NSW, Australia. \\ ${ }^{c}$ Environmental Earth Sciences International Pty Ltd, 82-84 Dickson Ave, Artarmon, NSW, Australia. \\ ${ }^{d}$ Centre for Carbon, Water and Food, The University of Sydney, Australia. \\ Email: fiona.tang@sydney.edu.au
}

\begin{abstract}
Expanding agricultural activities and industrial operations have resulted in the accumulation of toxic chemicals in our environment, and have become a potential threat to human health as well as to the flora and fauna in our ecosystems. The assessment of contamination risk to our environment mainly relies on mathematical models that estimate the contaminant concentrations and the leaching rates into aquifers. The contaminant level is commonly determined by comparing the concentrations predicted by models against a threshold concentration, and the ecosystem is considered at risk if the predicted contaminant concentration is above a threshold value. Although environmental models can describe contaminant transport and adsorption processes relatively well, most of these models do not take into account the capability of microorganisms to degrade toxic contaminants into less toxic or non-toxic molecules. Many experimental and in-situ studies have shown that soil microbial activity can result in a relatively fast rate of contaminant degradation, therefore implying that the time required to "clean-up" a contaminated site may be substantially shorter in the presence of receptive microorganisms. Hence, ecological risk assessments not accounting for microbial load and specific catabolic processes can overstate the risks and lead to the making of policies and management strategies only partly suitable to specific contaminated ecosystems.
\end{abstract}

In this study, we integrated the biodegradation potential $\psi_{B}$ of a contaminant into ecological risk assessment index through the specific biomass affinity $\phi$. We focused on atrazine (ATZ), one of the most extensively used herbicides in Australia, as the model contaminant using data from la Cecilia and Maggi (2017), and the Hazard Quotient as the modeled ecological risk index (Suter II, 2007). Model parameters were estimated from laboratory experiments, while simulations were extended to a 60-year time scale to analyze the Hazard Quotient of ATZ contamination in groundwater with the inclusion of ATZ biodegradation potential under scenarios of different ATZ application rates. These analyses demonstrated that ATZ contamination level can be overestimated if the biodegradation potential were not taken into account. The use of contaminant biodegradation potential in ecological risk assessments can improve information for optimum decision making in environment and resources management.

Keywords: Atrazine, agrochemicals, contamination, ecological risk index, specific biomass affinity 
Tang et al., Integrating biodegradation potential into ecological risk assessment index

\section{INTRODUCTION}

Although government agencies and industry organizations have invested a great effort in developing best management practices for handling chemical wastes and minimizing their impacts on ecosystems, traces of industrial and agricultural chemicals have been detected in the surface and ground water over the last few decades. For example, high concentrations of organochlorine compounds including dichloro-diphenyltrichloroethane (DDT), polychlorinated biphenyl (PCB), and hexachlorocyclohexane (HCH) have been detected in the Sydney Harbour catchment (Birch and Taylor, 2000), while atrazine (ATZ) concentrations above the Australian Drinking Water Guidelines threshold (i.e., $20 \mu \mathrm{g} / \mathrm{L}$; NRMMC, 2011) have been measured in groundwater in residential areas of Perth (Appleyard, 1995). These observations give rise to public concerns regarding the potential threat contaminants can impose on ecosystem and human health.

Many environmental risk assessment indices (e.g., Ecological Risk Index (ERI) and Hazard Quotient (HQ); Suter II, 2007) have been developed to quantify and predict the potential contamination risks on ecosystems. The majority of these indices consolidated the idea that the ecosystem health is at risk if the monitored or predicted contaminant concentrations are above a threshold concentration. The prediction of contaminant concentrations in decadal to centennial time scales often relies on mathematical models, which are expected to capture the dynamics of all physical, chemical, and biological processes in an ecosystem. However, most of the models include only contaminant transport and adsorption-desorption processes without accounting for biological processes. Many studies have documented the ability of microorganisms to change the information content, structure, properties, and chemical contents of geophysical systems (e.g., Jones et al., 1994; Eldridge and Greene, 1994; Tang and Maggi, 2017). Many experimental studies have shown that microorganisms can degrade contaminants into less toxic molecules (e.g., Leahy and Colwell, 1990; Coleman et al., 2002), and therefore models not accounting for biodegradation may overestimate the contamination level.

In this study, we described the biodegradation potential $\psi_{B}$ of a contaminant, and we incorporated its effect into an environmental risk assessment index. The parameter $\psi_{B}$ allows users to account for biodegradation without having to run a full biodegradation mechanistic model. The application of $\psi_{B}$ was then tested in a case study of atrazine (ATZ) contamination in West Wyalong, which is located in the "cereal belt" of New South Wales. Details of the site and model descriptions are presented in the following sections.

\section{METHODS OF PARAMETER ESTIMATION}

All model parameters were calibrated against existing experiments reported in the literature. Calibration was conducted with PEST (Doherty, 2005), which minimizes errors between model and experimental observations. The goodness-of-fit was measured using the $\mathrm{R}$-squared $\mathrm{R}^{2}=\left[\operatorname{cov}(x, y) /\left(\sigma_{x} \sigma_{y}\right)\right]^{2}$ and normalized root mean squared error NRMSE $=\left\{\sqrt{1 / n \sum_{i=1}^{n}\left(x_{i}-y_{i}\right)^{2}} /[\max (y)-\min (y)]\right\} \times 100$, where $x$ and $y$ are the modeled and experimental values, respectively, $n$ is the total number of observations, whereas, $\sigma_{x}$ and $\sigma_{y}$ are the standard deviation of $x$ and $y$, respectively.

\section{THE BIODEGRADATION POTENTIAL}

Using Michaelis-Menten-Monod kinetics, the capability of a specific microbial functional group $B$ with biomass concentration $[B]^{*}$ to degrade a substrate $S$ at low concentration can be expressed by the specific biomass affinity $\phi\left[\mathrm{T}^{-1}\right]$ (la Cecilia and Maggi, 2016)

$\phi=\lim _{\substack{[S] \rightarrow 0 \\[B] \rightarrow[B]^{*}}} \frac{\mu[B]}{Y\left([S]+K_{S}\right)}=\frac{\mu[B]^{*}}{Y K_{S}}$,

where $\mu\left[\mathrm{T}^{-1}\right]$ is the maximum specific biomass growth rate, $K_{S}\left[\mathrm{ML}^{-3}\right]$ is the Michaelis-Menten halfsaturation concentration, and $Y\left[\mathrm{MM}^{-1}\right]$ is the biomass yield per mole of consumed $S$. High values of $\phi$ indicate a rapid $S$ degradation and a shorter half time $t_{1 / 2}$ for $S$; that is, $1 / \phi \propto t_{1 / 2}$ as illustrated in Figure 1 (third column).

A sensitivity analysis of the effects of $\mu$ and $Y$ on $\phi$ and $t_{1 / 2}$ is presented in Figure 1 . The values of $\phi$ increased with increasing $\mu$ and decreasing $Y$ for unchanged $K_{S}$ and $[B]^{*}$. In a kinetic modeling framework that assumes stationary biomass content (i.e., $\mathrm{d}[B] / \mathrm{d} t \approx 0$ ), $1 / \phi$ and $t_{1 / 2}$ are strongly correlated with $\mathrm{R}^{2}=1.00$ (Figure 1, first row), whereas when biomass undergoes growth $\mathrm{d}[B] / \mathrm{d} t=-Y \mathrm{~d} S / \mathrm{d} t$ and mortality $\mathrm{d}[B] / \mathrm{d} t=$ $-\delta[B]$, the correlation between $1 / \phi$ and $t_{1 / 2}$ is weaker, i.e., $\mathrm{R}^{2} \approx 0.66$ (Figure 1 , second and third row). If microbial ecology and its dynamics in a natural environment were hypothesized to not dramatically vary over time, the specific biomass affinity $\phi$ can be used as a proxy to the biodegradation strength; hence, the 

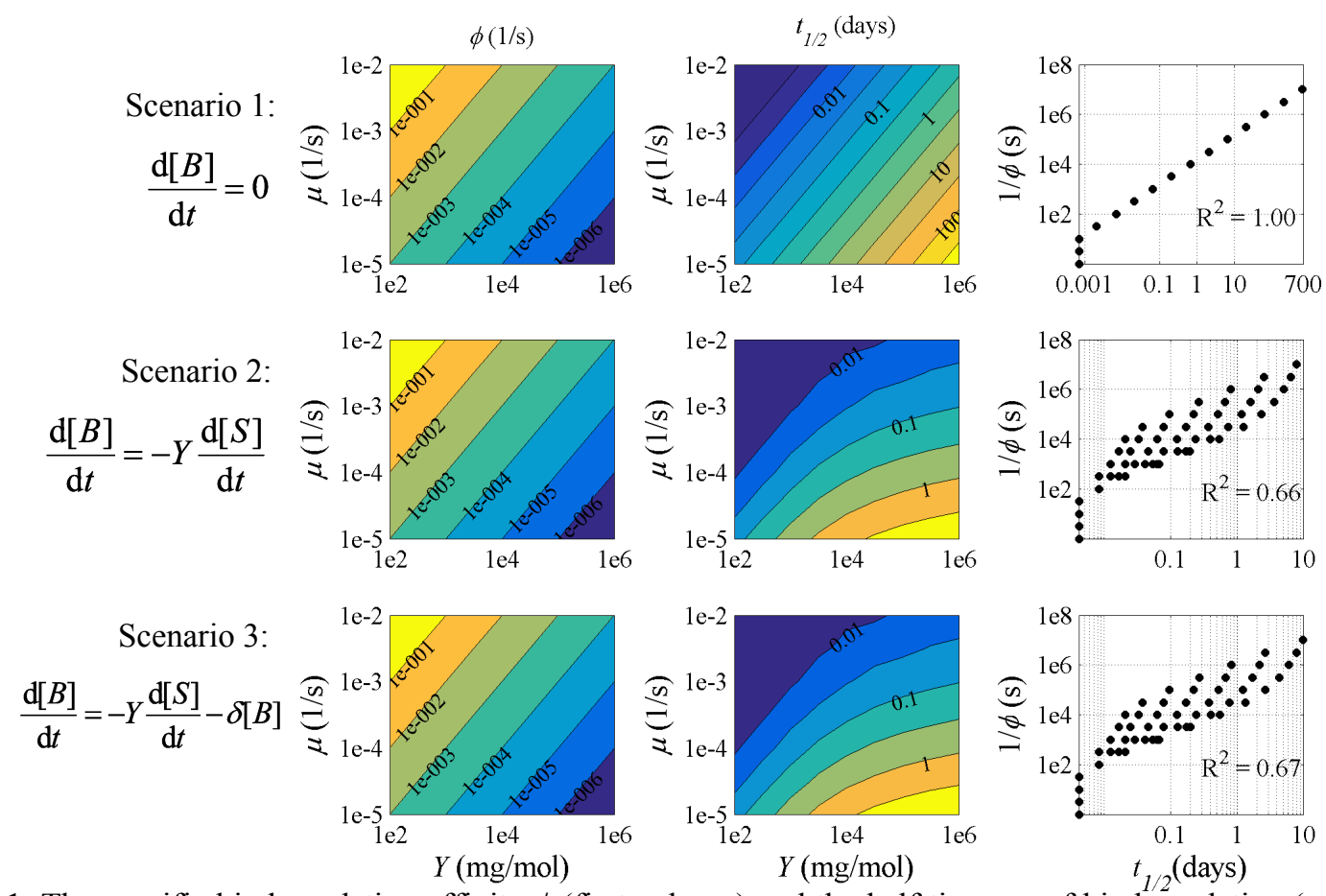

Figure 1. The specific biodegradation affinity $\phi$ (first column) and the half time $t_{1 / 2}$ of biodegradation (second column) at various values of specific growth rate $\mu$ and biomass yield $Y$ with the half-saturation concentration $K_{S}=1 \times 10^{-4} \mathrm{~mol} / \mathrm{L}$ and $[B]^{*}=1 \mathrm{mg} / \mathrm{L}$. Panels in the third column show the relationship between $1 / \phi$ and $t_{1 / 2}$. First row shows scenarios that consider no change in biomass over time. Second row represents scenarios considering biomass growth. Third row shows scenarios accounting for biomass growth and mortality.

biodegradation potential $\psi_{B}$ of $S$ by $n$ microbial functional groups can be expressed as,

$\psi_{B}=\frac{\sum_{i=1}^{n} \phi_{S, i}}{\phi_{r e f}}$,

where $\phi_{\text {ref }}$ is the reference specific biomass affinity that would result in a complete degradation of $S$. Note that, $\psi_{B}$ ranges between 0 and 1 , where $\psi_{B} \rightarrow 0$ indicates $S$ cannot be biodegraded and $\psi_{B} \rightarrow 1$ indicates $S$ can be fully biodegraded. Here, we propose to use the specific biomass affinity of glucose as the $\phi_{\text {ref }}$ because glucose is the preferred carbon source for most heterotrophic microorganisms. Michaelis-Menten-Monod kinetic parameters of aerobic glucose consumption $\left(\mu=1.71 \times 10^{-4} \mathrm{~s}^{-1}, K_{S}=8.15 \times 10^{-5} \mathrm{~mol} \mathrm{~L}^{-1}, Y=147580 \mathrm{mg}\right.$-wet $\mathrm{mol}^{-1}$ ) were estimated from experiments in Kremling et al. (2001).

The parameter $\psi_{B}$ in Eq. (2) can then be incorporated into ecological risk assessment indices to account for biodegradation. In this work, we used the Hazard Quotient HQ (Suter II, 2007) defined as

$\mathrm{HQ}=\frac{\left(1-\psi_{B}\right) C_{\text {predicted }}}{C_{\text {threshold }}}$,

where $C_{\text {predicted }}$ is the predicted environmental concentration of a contaminant in the absence of biodegradation and $C_{\text {threshold }}$ is the threshold concentration for no adverse effect.

\section{CASE STUDY OF ATRAZINE CONTAMINATION}

\subsection{Site description and application scenarios}


The use of $\psi_{B}$ to assess atrazine (ATZ) contamination was numerically tested in an agricultural site at West Wyalong (about $470 \mathrm{~km}$ West of

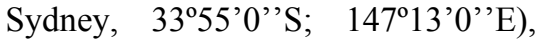
NSW, Australia. The test site is classified as clay in the top $1.5 \mathrm{~m}$, loamy sand from 1.5 to $5 \mathrm{~m}$ depth, and shale below $5 \mathrm{~m}$ depth (JRC, 2012), with soil properties and hydraulic parameters summarized in Table 1.
Table 1. Soil properties and hydraulic parameters at West Wyalong, NSW, Australia. *Data obtained from the Harmonized World Soil Database (JRC, 2012). **Estimated using van Genuchten (1980). ***Estimated as in Maggi (2015).

\begin{tabular}{|l|l|l|}
\hline *Depth (m) & $0-1.5$ & $1.5-5$ \\
\hline *Soil texture & Clay & Loamy sand \\
\hline *Sand-silt-clay fraction & $15 \%-28 \%-57 \%$ & $80 \%-10 \%-10 \%$ \\
\hline$*$ Bulk density $\left(\mathbf{k g} / \mathbf{m}^{3}\right)$ & 1370 & 1350 \\
\hline$*$ Porosity & 0.47 & 0.50 \\
\hline$* * \mathbf{m}$ & 1.43 & 1.74 \\
\hline$* * \boldsymbol{\alpha}(\mathbf{1} /$ Pa) & $2.14 \times 10^{-4}$ & $2.37 \times 10^{-4}$ \\
\hline$* * *$ Permeability $\left.\mathbf{( m}^{\mathbf{2}}\right)$ & $0.16 \times 10^{-12}$ & $1.58 \times 10^{-12}$ \\
\hline
\end{tabular}

The precipitation and potential evapotranspiration rates in the period between 1990 and 2015 obtained from the Bureau of Meteorology (2016) were used to construct time sequences that extended for 60 years. Precipitation events that exceeded 15 years return time were substituted with the mean value to avoid repetition of unlikely events. The actual crop evapotranspiration during the growing season was determined by multiplying the time-varying crop coefficient of wheat $\left(K_{C}=0.5-0.6\right)$ by the potential evapotranspiration, while $K_{C}=0.3$ was used in the absence of crops. The root density distribution was assumed to be a negative exponential function down to $1.5 \mathrm{~m}$ with an average depth at $0.3 \mathrm{~m}$. In the model, ATZ was applied yearly at application rates $r_{A T Z}$ ranging between 0.5 and $8.0 \mathrm{~kg} / \mathrm{ha}$ for 60 years. ATZ leaching to an intermittent shallow groundwater ( $1.0 \mathrm{~m}$ thickness $)$ at $4 \mathrm{~m}$ depth at the end of the 60 -year application was analyzed.

\subsection{Model description}

The model was solved in the general-purpose multiphase and multicomponent bio-reactive transport solver BRTSim-v2.2 (Maggi, 2015). The model considers only the ATZ vertical transport and its adsorption-desorption processes. Weekly-averaged precipitation, wheat actual evapotranspiration, and irrigation were applied as the upper boundary conditions. Water flow in the vertical direction was solved with the Richards equation, while ATZ transport was modeled by Darcy's advection and Fick's diffusion (e.g., Maggi, 2015; Tang and Maggi, 2016). The adsorption-desorption processes were modeled using Langmuir kinetics (Atkins and De Paula, 2005), such that

$\frac{\mathrm{d}[\mathrm{ATZ}]_{a d}}{\mathrm{~d} t}=k_{a}[\mathrm{ATZ}]_{a q}\left(Q_{m}-[\mathrm{ATZ}]_{a d}\right)-k_{d}[\mathrm{ATZ}]_{a d}$,

where $[\mathrm{ATZ}]_{a d}$ and $[\mathrm{ATZ}]_{a q}$ are atrazine concentrations in adsorbed and aqueous phases, respectively, $k_{a}\left[\mathrm{~L}^{3} \mathrm{M}^{-1} \mathrm{~T}^{-1}\right]$ and $k_{d}\left[\mathrm{~T}^{-1}\right]$ are the adsorption and desorption rate constants, respectively, and $Q_{m}=q_{m} C_{\text {soil }}$ with $q_{m}\left[\mathrm{MM}^{-1}\right]$ the maximum adsorption per unit mass and $C_{\text {soil }}$ the soil concentration. At equilibrium $\left(\mathrm{d}[\mathrm{ATZ}]_{a d} / \mathrm{d} t=0\right), K_{L}=k_{a} / k_{d}$ is the Langmuir equilibrium constant $\left[\mathrm{L}^{3} \mathrm{M}^{-1}\right]$. The model considered only ATZ adsorption to clay and silt fractions, assuming that adsorption to sand was negligible.

Langmuir kinetics parameters $k_{a}, k_{d}$, and $q_{m}$ in Eq. (4) for ATZ were calibrated against experiments in Vryzas et al. (2007) for a soil consisting of $64 \%$ clay, $17 \%$ silt, and $19 \%$ sand monitored over time at $22^{\circ} \mathrm{C}$. The estimated parameters were $k_{a}=4.02 \mathrm{~L} \mathrm{~mol}^{-1} \mathrm{~s}^{-1}, k_{d}=1.98 \times 10^{-5} \mathrm{~s}^{-1}, K_{L}=2.03 \times 10^{5} \mathrm{~L} \mathrm{~mol}^{-1}$, and $q_{m}=5.79 \times 10^{-}$ ${ }^{9} \mathrm{~mol} \mathrm{~g}^{-1}$ (Figure 3).

\subsection{Biodegradation potential of ATZ}

Experiments showed that ATZ can be degraded by two soil microbial functional groups, i.e., the hydrolytic $B_{A T Z h y d}$ and oxidative ATZ degraders $B_{\text {ATZoxi }}$ (la Cecilia and Maggi, 2017). B $B_{\text {ATZhyd }}$ (e.g., Pseudomonas sp. ADP and Nocardia sp.) can hydrolyze ATZ to hydroxyatrazine (HOATZ) under both aerobic and anaerobic conditions (e.g., Mandelbaum et al., 1995; Smith et al., 2005; Katz et al., 2000). B ATZoxi (e.g., Rhodococcus, Enterobacter cloacae strain JS08.Deg01) can catabolize ATZ via two different pathways to either deisopropylatrazine (DIATZ) or deethylatrazine (DEATZ) in aerobic condition (e.g., Shao et al., 1995; Soloman et al., 2013). A comprehensive ATZ biodegradation network with Michaelis-Menten-Monod kinetic parameters calibrated against laboratory experiments was reported in la Cecilia and Maggi (2017), while a summary of the parameters is presented in Table 2. 
Tang et al., Integrating biodegradation potential into ecological risk assessment index

Table 2. Michaelis-Menten-Monod kinetic parameters of ATZ biodegradation (la Cecilia and Maggi, 2017).

\begin{tabular}{|c|c|c|c|c|c|c|c|}
\hline $\begin{array}{c}\text { Microbial } \\
\text { functional } \\
\text { group }\end{array}$ & $\begin{array}{c}\text { End- } \\
\text { product }\end{array}$ & Respiration & $\mu\left(\mathrm{s}^{-1}\right)$ & $K_{S}\left(\mathbf{m o l ~ L}^{-1}\right)$ & $\begin{array}{c}Y \\
\left(\mathrm{mg} \text {-wet } \mathrm{mol}^{-1}\right)\end{array}$ & $\begin{array}{c}\phi^{\prime}=\mu /\left(K_{S} \times Y\right) \\
\left(\mathbf{L ~} \mathrm{mg}^{-1} \mathbf{s}^{-1}\right)\end{array}$ & $\begin{array}{l}\text { Average } \phi^{\prime} \\
\left(\mathrm{L} \mathrm{mg}^{-1} \mathrm{~s}^{-1}\right)\end{array}$ \\
\hline \multirow[t]{2}{*}{$B_{\text {ATZhyd }}$} & \multirow[t]{2}{*}{ HOATZ } & Aerobic & $3.67 \times 10^{-5}$ & $3.89 \times 10^{-4}$ & $2.98 \times 10^{5}$ & $3.17 \times 10^{-7}$ & \multirow[t]{2}{*}{$1.12 \times 10^{-5}$} \\
\hline & & Anaerobic & $2.31 \times 10^{-6}$ & $3.43 \times 10^{-6}$ & $3.06 \times 10^{4}$ & $2.20 \times 10^{-5}$ & \\
\hline \multirow[t]{2}{*}{$B_{\text {ATZoxi }}$} & DIATZ & Aerobic & $1.61 \times 10^{-4}$ & $2.25 \times 10^{-3}$ & $7.22 \times 10^{4}$ & $9.91 \times 10^{-7}$ & \multirow[t]{2}{*}{$1.21 \times 10^{-6}$} \\
\hline & DEATZ & Aerobic & $1.51 \times 10^{-4}$ & $2.09 \times 10^{-3}$ & $5.06 \times 10^{4}$ & $1.43 \times 10^{-6}$ & \\
\hline
\end{tabular}

By using the ATZ kinetic parameters in Table 2 and the specific biomass affinity of glucose as $\phi_{\text {ref, }}$, the effect of $B_{A T Z h y d}$ and $B_{A T Z o x i}$ concentrations on ATZ biodegradation potential $\psi_{B}$ was analyzed and depicted in Figure 5. The analysis was conducted by assuming that the total biomass in soil is capable of degrading ATZ, i.e., $\left[B_{\text {Total }}\right]=\left[B_{A T Z}\right]=$ $\left[B_{\text {ATZhyd }}\right]+\left[\mathrm{B}_{\text {ATZoxi }}\right]=100 \mathrm{mg}$-wet $/ \mathrm{kg}$-soil, which is the biomass concentration typically found in soil (Raynaud and Nunan, 2014). Figure 4 shows that $\psi_{B}$ increased with increasing $\left[B_{\text {ATZhyd }}\right]$ and decreasing [ $\left.\mathrm{B}_{\text {ATZoxi }}\right]$ because $B_{\text {ATZhyd }}$ has significantly higher $\phi^{\prime}$ [i.e., $\phi^{\prime}=\mu /\left(K_{S} \times Y\right)$ ] than $B_{\text {ATZoxi }}$; this therefore suggests that the ecology of soil microorganisms can affect the biodegradation potential of a contaminant.

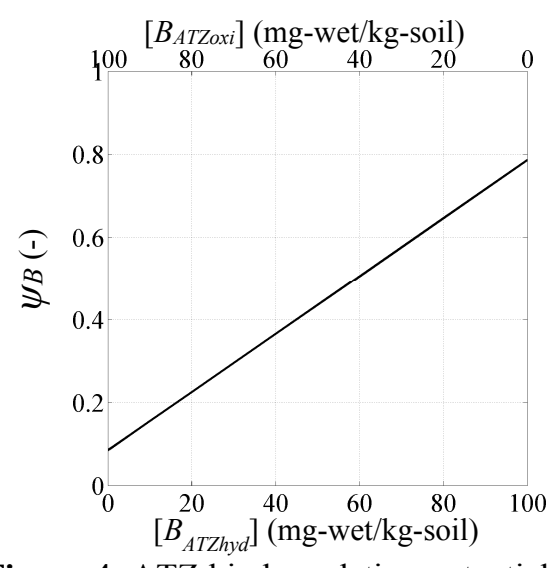

Figure 4. ATZ biodegradation potential $\psi_{B}$ at various concentrations of $B_{A T Z h y d}$ and $B_{A T Z o x i}$.

\subsection{Analyses of ATZ leaching}

ATZ leaching to the shallow groundwater at $4 \mathrm{~m}$ depth after 60 years of applications at different rates was analyzed using the model without biodegradation described in Section 4.2. At the lowest application rate (i.e., $r_{A T Z}=0.5 \mathrm{~kg} \mathrm{ha}^{-1}$ year $^{-1}$ ), approximately $58 \%$ of ATZ applied was immobilized by adsorption onto soil, whereas, the fraction of applied ATZ that could be immobilized decreased exponentially with increasing $r_{A T Z}$ (Figure 5a). ATZ was found to be mainly adsorbed in the top $1.5 \mathrm{~m}$ of the soil column, which was rich in silt and clay (Figure 5b). A portion of ATZ in the aqueous phase leached into the aquifer at the end of the 60year simulation period. ATZ concentrations in the shallow groundwater increased with increasing $r_{A T Z}$ (Figure 5c). ATZ found in groundwater exceeded $C_{\text {threshold }}$ suggested by Australian drinking water guidelines (i.e., $0.02 \mathrm{mg} / \mathrm{L}$; NRMMC, 2011) when $r_{A T Z}>2 \mathrm{~kg} \mathrm{ha}^{-1}$ year ${ }^{-1}$, an application rate commonly used in agriculture.

The Hazard Quotient (HQ) for ATZ contamination in the groundwater after 60-year ATZ applications was determined using Eq. (3), where ATZ biodegradation potential $\psi_{B}$ was incorporated into the risk assessment index. Here, $C_{\text {threshold }}=0.02 \mathrm{mg} / \mathrm{L}$ was used as per the Australian drinking water guidelines (NRMMC, 2011), and the total biomass concentration in soil $\left[B_{\text {Total }}\right]$ was assumed to be $100 \mathrm{mg}$-wet $/ \mathrm{kg}$-soil after Raynaud and Nunan (2014). We assumed that all $B_{\text {Total }}$ can degrade glucose, but only a fraction $\gamma$ of $B_{\text {Total }}$ are ATZ degraders, i.e., $\left[B_{A T Z}\right]=\gamma\left[B_{\text {Total }}\right]=\left[B_{A T Z h y d}\right]+\left[\mathrm{B}_{\mathrm{ATZ} \text { oxi }}\right]$. Note that, $\psi_{B}=0$ when $\left[B_{A T Z}\right]=0$, signifying that ATZ cannot be biodegraded.
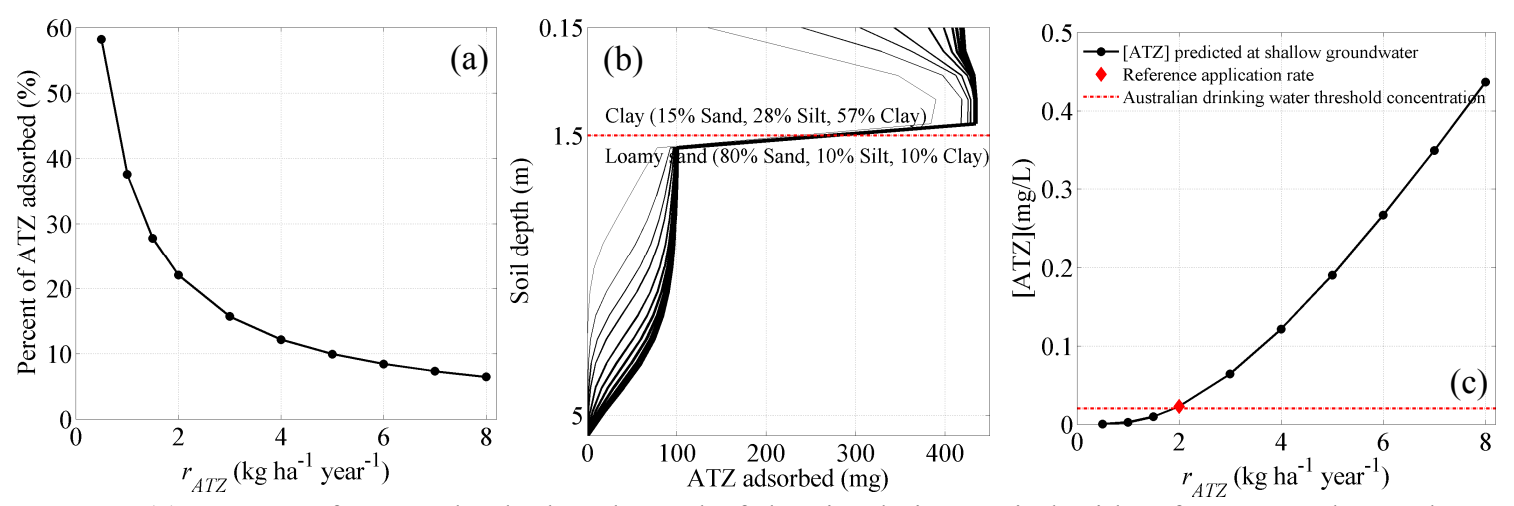

Figure 5. (a) Percent of ATZ adsorbed at the end of the simulation period with reference to the total ATZ applied in 60 years, (b) ATZ adsorbed mass at different soil depth at the end of the 60-year simulation for different ATZ application rates $r_{A T Z}$ (i.e., $r_{A T Z}$ increased with increasing line thickness), and (c) predicted ATZ concentration in the shallow groundwater after 60 years of ATZ application. 
In general, HQ decreased with increasing $\left[B_{A T Z}\right]$ (Figure 6). The decrease in HQ values was especially remarkable in the case where all ATZ degraders were hydrolytic (Figure 6a), while HQ values were not significantly decreased when $B_{\text {ATZhyd }}$ were not present in the microbial community even though $B_{A T Z o x i}$ existed (Figure 6b). These results show that the index HQ after the incorporation of parameter $\psi_{B}$ as in Eq. (3) can capture the biodegradation capacity of a microbial population with different ecology.

The uncertainties associated with HQ may arise from several aspects, including kinetic parameters estimation, the choice of $\phi_{r e f}$, soil properties measurement, variations in hydrometeorological characteristics, and the estimation of degrader concentrations. For example, the kinetic parameters of ATZ biodegradation used in this study had standard deviations of about 50\% (la Cecilia and Maggi, 2017), while variations in soil properties and hydrometeorological characteristics of a test site can affect the prediction of contaminant transport and immobilization. Although concentration of degraders can be laboratory estimated from field samples, its spatial heterogeneity may cause uncertainty in the prediction using HQ. These uncertainties can be quantified through stochastic global analysis, which is not presented in this work.
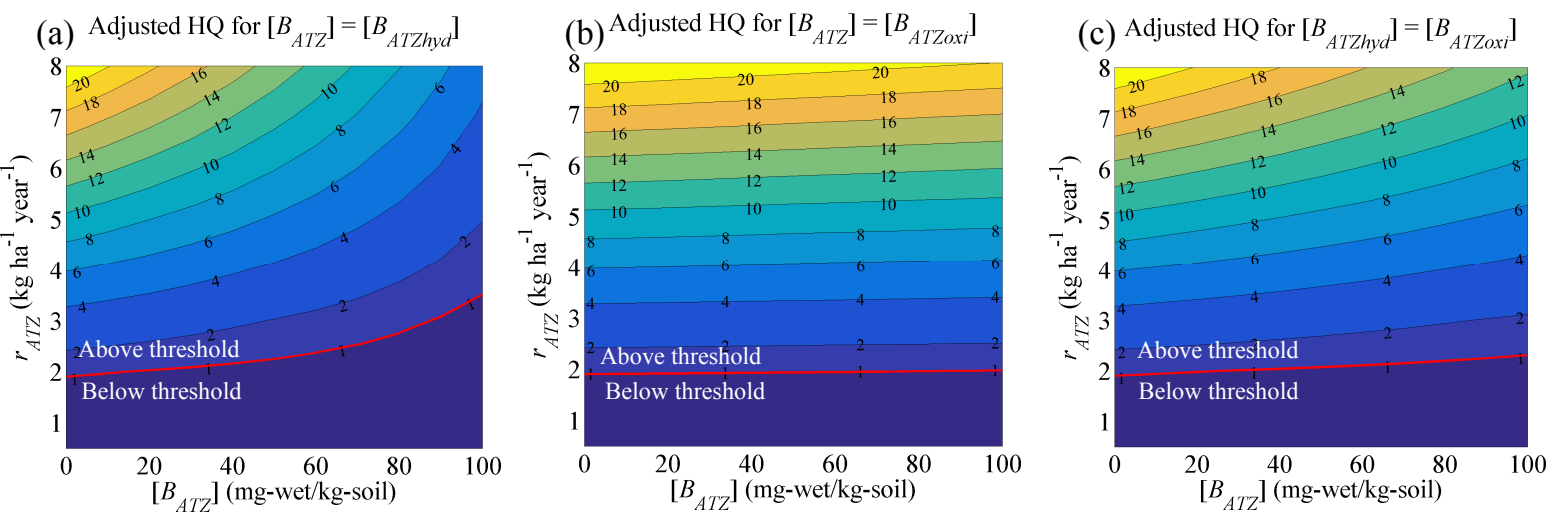

Figure 6. The Hazard Quotient HQ of Eq. (3) for ATZ contamination at $4 \mathrm{~m}$ shallow groundwater in West Wyalong, NSW after 60 years of ATZ application with scenarios where (a) all ATZ degraders are hydrolytic, (b) all ATZ degraders are oxidative, and (3) the ratio of hydrolytic to oxidative degraders was $1: 1$. Note, $\left[B_{A T Z}\right]$ $=\gamma\left[B_{\text {Total }}\right]$ with $\left[B_{\text {Total }}\right]=100 \mathrm{mg}$-wet $/ \mathrm{kg}$-soil and $\gamma$ ranged between 0 and 1 . The red solid line represents $\mathrm{HQ}=1$.

\section{CONCLUSIONS}

In this study, we proposed to incorporate a parameter that accounts for contaminant biodegradation potential into the risk assessment indices. The biodegradation potential $\psi_{B}$ parameter is defined based on the specific biomass affinity $\phi$ of the contaminant, which relates the specific growth rate $\mu$ and Michaelis-Menten half saturation concentration $K_{S}$ of a biochemical reaction to the biomass yield $Y$ and biomass concentration of the microbial functional groups that carry out the reaction. In this study, we used atrazine as the model contaminant, West Wyalong, NSW, as the test site, and the Hazard Quotient (HQ) as the modeled ecological risk assessment index to test the applicability of $\psi_{B}$ on the assessment of ATZ contamination level in groundwater after 60 years of ATZ application at different rates. We demonstrated that $\phi$ is inversely proportion to the half time of a contaminant and therefore, it can be used to describe the contaminant biodegradation potential $\psi_{B}$. We also showed that HQ is sensitive to biomass concentrations and the dynamics of the microbial ecology when it accounts for $\psi_{B}$. HQ generally decreased with the increase in the concentrations of the degraders.

\section{ACKNOWLEDGMENTS}

This project is supported by the Sydney Research Excellence Initiative (SREI 2020) of The University of Sydney. The BRTSim solver package can be downloaded at link https://www.dropbox.com/sh/wrfspx9f1dvuspr/AAD5iA9PsteX3ygAJxQDxAy9a?dl=0.

\section{REFERENCES}

Appleyard, S. J. (1995). Investigation of ground water contamination by fenamiphos and atrazine in a residential area: source and distribution of contamination. Groundwater Monitoring and Remediation, 15(4), 110-113.

Atkins P., and De Paula J., (2005). Elements of physical chemistry. Oxford University Press, USA, ${ }^{\text {th }}$ edition. 
Tang et al., Integrating biodegradation potential into ecological risk assessment index

Birch G.F., and Taylor S.E., (2000). Distribution and possible sources of organochlorine residues in sediments of a large urban estuary, Port Jackson, Sydney. Australian Journal of Earth Sciences, 47(4), 749-756.

Bureau of Meteorology, (2016). http://www.bom.gov.au/climate/data/index.shtml. Accessed on 26.05.2016.

Coleman N.V., Mattes T.E., Gossett J.M., and Spain J.C., (2002). Phylogenetic and kinetic diversity of aerobic vinyl chloride-assimilating bacteria from contaminated sites. Applied and Environmental Microbiology, 68(12), 6162-6171.

Doherty J., (2005). PEST: Model-independent parameter estimation. Watermark Computing, Corinda, Australia, $5^{\text {th }}$ edition.

Eldridge D.J., and Greene R.S.B., (1994). Microbiotic soil crusts-a review of their roles in soil and ecological processes in the rangelands of Australia. Soil Research, 32(3), 389-415.

Jones C.G., Lawton J.H., and Shachak M., (1994). Organisms as ecosystem engineers. In Ecosystem Management,130-147, Springer New York.

JRC, (2012). Harmonized World Soil Database (version 1.2). FAO, Rome, Italy and IIASA, Laxenburg, Austria.

Katz I., Green M., Ruskol Y., and Dosoretz C.G., (2000). Characterization of atrazine degradation and nitrate reduction by Pseudomonas sp. strain ADP. Advances in Environmental Research, 4(3), 211-218.

Kremling A., Bettenbrock K., Laube B., Jahreis K., Lengeler J.W., and Gilles E.D., (2001). The organization of metabolic reaction networks: III. Application for diauxic growth on glucose and lactose. Metabolic Engineering, 3(4), 362-379.

la Cecilia D., and Maggi F., (2016). Kinetics of atrazine, deisopropylatrazine, and deethylatrazine soil biodecomposers. Journal of Environmental Management, 183, 673-686.

la Cecilia D., and Maggi F., (2017). In-situ atrazine biodegradation dynamics in wheat (Triticum) crops under variable hydrologic regime. Journal of Contaminant Hydrology.

Leahy J.G., and Colwell R.R., (1990). Microbial degradation of hydrocarbons in the environment. Microbiological Reviews, 54(3), 305-315.

Maggi F., (2015). BRTSim version 1; A general-purpose multiphase and multicomponent computational solver for biogeochemical reaction-advection-dispersion processes in porous and non-porous media, 1st edition., Research Report R954, The University of Sydney, Australia.

Mandelbaum R.T., Allan D.L., and Wackett L.P., (1995). Isolation and characterization of a Pseudomonas sp. that mineralizes the s-triazine herbicide atrazine. Applied and Environmental Microbiology, 61(4), 1451-1457.

NRMMC, (2011). Australian Drinking Water Guidelines Paper 6 National Water Quality Management Strategy. National Health and Medical Research Council, National Resource Management Ministerial Council, Commonwealth of Australia, Canberra.

Raynaud X., and Nunan N., (2014). Spatial ecology of bacteria at the microscale in soil. PLoS One, 9(1), e87217.

Shao Z.Q., Seffens W., Mulbry W., and Behki R.M., (1995). Cloning and expression of the s-triazine hydrolase gene (trzA) from Rhodococcus corallinus and development of Rhodococcus recombinant strains capable of dealkylating and dechlorinating the herbicide atrazine. Journal of Bacteriology, $177(20), 5748-5755$.

Smith D., Alvey S., and Crowley D.E., (2005). Cooperative catabolic pathways within an atrazine-degrading enrichment culture isolated from soil. FEMS Microbiology Ecology, 53(2), 265-273.

Solomon R.D.J., Kumar A., and Santhi V.S., (2013). Atrazine biodegradation efficiency, metabolite detection, and trzD gene expression by enrichment bacterial cultures from agricultural soil. Journal of Zhejiang University SCIENCE B, 14(12), 1162-1172.

Suter II G.W., (2007). Ecological Risk Assessment $2^{\text {nd }}$ Edition. CRC Press, New York.

Tang F.H.M., and Maggi F., (2016). Breakdown, uptake and losses of human urine chemical compounds in barley (Hordeum vulgare) and soybean (Glycine max) agricultural plots. Nutrient Cycling in Agroecosystems, 104(2), 221-245.

Tang F.H.M., and Maggi F., (2017). Living microorganisms change the information (Shannon) content of a geophysical system. Scientific Reports, 7.

van Genuchten M.T., (1980). A closed-form equation for predicting the hydraulic conductivity of unsaturated soils. Soil Science Society of America Journal, 44(5), 892-898.

Vryzas Z., Papadopoulou-Mourkidou E., Soulios G., and Prodromou K., (2007). Kinetics and adsorption of metolachlor and atrazine and the conversion products (deethylatrazine, deisopropylatrazine, hydroxyatrazine) in the soil profile of a river basin. European Journal of Soil Science, 58(5), 1186-1199. 